\title{
Ordered mesoporous carbon provoked dimensionally varied molybdenum dichalcogenide: A striking sensing matrix for electrochemical detection of hydrazine
}

\author{
Sankararao Mutyala ${ }^{1,2} \cdot$ Chinnathambi Suresh $^{1}$ (D) Jayaraman Mathiyarasu ${ }^{1}$
}

Received: 26 March 2020 / Accepted: 9 June 2020 / Published online: 16 June 2020

(c) Springer Nature Switzerland AG 2020

\begin{abstract}
Rational design and construction of two-dimensional transition metal dichalcogenides (TMDs) with minimal size are vital for improving the sensitivity and selectivity of the electrochemical sensors. Here we demonstrated a vast surface triggered size reduced $\mathrm{MoS}_{2}$ formation on ordered mesoporous carbon (OMC) support. The OMC support material was synthesized through hard templating approach using mesoporous silica SBA-15. Subsequently, the $\mathrm{MoS}_{2}-\mathrm{OMC}$ nanocomposite material was obtained through hydrothermal route. The structural properties of the prepared materials prove the existence of a well-defined mesoporous nature of carbon and flower-like $\mathrm{MoS}_{2}$ on the surface of OMC. The developed $\mathrm{MoS}_{2}$-OMC composite was deployed as a sensing matrix for the detection of hydrazine in neutral medium. The electrochemical results illustrated that the prepared composite materials exhibited excellent activity towards hydrazine detection with a wide linear detection range (1-9 $\mu \mathrm{M})$ and very low detection limit of $0.4 \mu \mathrm{M}$ with a sensitivity of 0.25 $\mu \mathrm{A} / \mu \mathrm{M}$ respectively.
\end{abstract}

Keywords $\mathrm{MoS}_{2} \cdot$ Mesoporous carbon · Composite structure $\cdot$ Hydrazine sensor

\section{Introduction}

Hydrazine is an essential chemical that has been widely used in various applications like antioxidants, emulsifiers, and rocket propellants. However, its exposure to the human system affects them in many ways [1, 2]. Due to hazardous nature, it is very essential to develop a detection protocol for a selective and sensitive determination of hydrazine. So far numerous methods such as fluorescent assay [3], titrimetry [4], potentiometry [5], chromatography [6], flow injection analysis [7] and electrochemical technique have been utilized for the determination of hydrazine. Among all, the electrochemical technique is the best method because of its high sensitivity, fast response, affordability, and real-time utility [8-11]. However, the electrochemical hydrazine oxidation at unmodified electrodes is restricted due to sluggish kinetics and requires very high overpotential, which ends up with a poor sensing performance [12]. To overcome this, a strategy of utilizing single or composite electroactive nanomaterials with enhanced sensitivity and selectivity was proposed [13, 14]. Numerous composite materials were tested for detecting a vast spectrum of biomolecules; it includes the most studied glucose $[15,16]$ and hydrogen peroxide $[17,18]$. In the recent scenario, the unique two-dimensional transition metal dichalcogenides (TMDs) such as $\operatorname{MoS}_{2}, \mathrm{WS}_{2}$, and $\mathrm{MoSe}_{2}$, etc., have been attracted much attention in a huge number of applications including electronics [19, 20] electrocatalysis [21, 22] electrochemical sensors [23, $24]$ and electrochemical energy-related applications [ 25 ,

Chinnathambi Suresh, csuresh@cecri.res.in | ${ }^{1}$ Electrodics and Electrocatalysis Division, CSIR- Central Electrochemical Research Institute, Karaikudi, Tamil Nadu 630 003, India. ${ }^{2}$ Department of Chemistry, Koneru Lakshmaiah Education Foundation (KLEF), Vaddeswaram, Guntur, Andhra Pradesh 522 502, India. 
26]. Within the group, the layered $\mathrm{MoS}_{2}$ structure attracted much interest in electrochemical applications. With the existence of a wide tunable bandgap nature of materials, it shows excellent electronic properties [27, 28]. Altering the bandgap by doping with foreign metals leads to significant physicochemical properties $[29,30]$. Meanwhile, reducing the size in a single layer or by quantum size, important properties like photoluminescence were observed [31, 32]. Recently these $\mathrm{MoS}_{2}$ layered structures have highly emerged in the field of electrochemical sensors for the detection of the bioanalytes [33, 34]. The available literature pointed out that though these materials show excellent electrochemical activity, miniaturization into individual slap leads to enhanced activity. Therefore, different synthetic routes are attempted for the development of single slap $\mathrm{MoS}_{2}$ [35]. Further, the fabrication of electrochemical devices for sensor and catalysis applications using homogenized single-layer $\mathrm{MoS}_{2}$ is still a challenging task. As such, in our previous work, we demonstrated that the hydrothermal growth of $\mathrm{MoS}_{2}$ on the silica support shows significant advantages than the unsupported one [36]. In this present work, further scale-up of $\mathrm{MoS}_{2}$ for electrochemical application is attempted and the unique $\mathrm{MoS}_{2}-\mathrm{OMC}$ composite electrode is fabricated for electrochemical sensing applications. The prepared composite materials showed well structural characteristics and the electrochemical sensor activity was verified with hydrazine.

\section{Materials and methods}

\subsection{Chemicals and materials}

The analytical reagent (AR) grade chemicals were purchased by global suppliers such as Merck and SigmaAldrich. All the chemicals were used as received without further purification. Meanwhile, the solutions which are utilized for electrochemical sensing studies were prepared using milli-Q $(18.2 \mathrm{M} \Omega \mathrm{cm})$ water.

\subsection{Synthesis of mesoporous silica (SBA-15) and mesoporous carbon (OMC)}

The micellar mechanism was adopted for the synthesis of SBA-15 material. Here, the Pluronic $\mathrm{P} 123\left(\mathrm{EO}_{20} \mathrm{PO}_{70} \mathrm{EO}_{20}\right)$ co-polymer, [Aldrich, $\mathrm{Mw}=5800$ ] and tetraethyl orthosilicate (TEOS) were used as a structure-directing agent and silica source respectively. In a typical synthesis, $3 \mathrm{~g}$ of Pluronic P123 was dispersed in a calculated amount of distilled water, and the resultant solution is mixed with $2 \mathrm{M} \mathrm{HCl}$ at $40{ }^{\circ} \mathrm{C}$. Then $6.3 \mathrm{~g}$ of TEOS was added to the above resultant solution. The mixture was stirred at $40{ }^{\circ} \mathrm{C}$ for $24 \mathrm{~h}$ and then aged at $100^{\circ} \mathrm{C}$ for $48 \mathrm{~h}$ without stirring. The obtained solid product was recovered by filtration, washed with deionized water and dried at $80^{\circ} \mathrm{C}$ overnight. Calcination was carried out in static air at $550^{\circ} \mathrm{C}$ for $8 \mathrm{~h}$. [37]. Meanwhile, the OMC materials were prepared by a hard-templating approach by utilizing mesoporous silica SBA-15 as a hard template. In detail, a calculated amount of sucrose, sulfuric acid, and water were mixed with $1 \mathrm{~g}$ of mesoporous silica and the mixture was stirred for $12 \mathrm{~h}$ at room temperature. This mixture was dried at $100^{\circ} \mathrm{C}$ for $6 \mathrm{~h}$, after that the oven temperature was increased to $160^{\circ} \mathrm{C}$ and kept it for another $6 \mathrm{~h}$. Similar steps were repeated to completely cover the mesoporous silica surface by carbon precursors. Finally, the as-synthesized silica-carbon composite was carbonized at $900{ }^{\circ} \mathrm{C}$ for $4 \mathrm{~h}$ at the inert gas atmosphere and the silica template was removed using hot $\mathrm{NaOH}$ solution.

\subsection{Synthesis of $\mathrm{MoS}_{2}-\mathrm{OMC}$ composite}

The hydrothermal synthesis was adopted for the $\mathrm{MoS}_{2}$-OMC composite formation. In a typical synthesis, $0.15 \mathrm{~g}$ of sodium molybdate, $0.18 \mathrm{~g}$ of thiourea and $0.016 \mathrm{~g}$ of polyethylene glycol were dissolved in a calculated quantity of deionized water. The entire mixture was stirred for $2 \mathrm{~h}$ and then $0.4 \mathrm{~g}$ of OMC support was added to the above mixture and further stirred for $12 \mathrm{~h}$. The final mixture was transferred into a Teflon lined autoclave and hydrothermally heated at $180^{\circ} \mathrm{C}$ for $24 \mathrm{~h}$. The as-synthesized product of $\mathrm{MoS}_{2}-\mathrm{OMC}$ was washed and dried at $80^{\circ} \mathrm{C}$ for $12 \mathrm{~h}$.

\subsection{Characterization}

The structure and phase formation of $\mathrm{OMC}, \mathrm{MoS}_{2}$, $\mathrm{MoS}_{2}$-OMC composite material was characterized by an $X$-ray diffractometer (Bede Scientific Ltd., UK; CuKa radiation; operated at $40 \mathrm{kV}, 45 \mathrm{~mA} ; \mathrm{I}=0.15418 \mathrm{~nm})$. In XRD analysis, the diffraction angle was measured ranging from 10 to $802 \theta$ value. The vibrational characteristics of the synthesized samples were verified using Renishaw Invia Raman Microscopy. He-Ne laser source of $632.8 \mathrm{~nm}$ wavelength and $18 \mathrm{~mW}$ intensity was utilized to measure the Raman features of the samples. Morphological features of $\mathrm{MoS}_{2}$ and composite materials were characterized by (FESEM, ZEEIS X-Max Oxford Instruments) and TEM using Tecnai G20, operating at $200 \mathrm{kV}$. The oxidation state and composition were examined using $\mathrm{X}$-ray photoelectron spectroscopy (XPS). The Multilab 2000 Thermo scientific (UK) X-ray photoelectron spectrometer with Mg Ka X-ray $(1253.6 \mathrm{eV})$ and $200 \mathrm{~W}$ power was used as the exciting source and $10 \mathrm{eV}$ energy pass was used for data collection. 


\subsection{Electrochemical sensor activity studies}

The Potentiostat/Galvanostat BAS 100B (Bioanalytical Systems Inc.) was utilized for the electrochemical experiment. All the electrochemical sensing experiments were carriedout at an ambient temperature $\left(25 \pm 1^{\circ} \mathrm{C}\right)$ using a threeelectrode system. In detail, a glassy carbon electrode (GCE) modified with the catalyst ink served as working electrode. The standard $\mathrm{Ag} / \mathrm{AgCl}(3 \mathrm{M} \mathrm{KCl})$ and Pt wire served as reference and counter electrodes respectively. The catalyst ink was prepared by mixing $1 \mathrm{mg}$ of synthesized materials with $5 \mu$ l of Nafion ( $5 \mathrm{wt} \%$ ) solution and $1 \mathrm{ml}$ of water. The mixture was sonicated for an hour and $3 \mu \mathrm{l}$ of this ink was drop cast on the GCE and dried at room temperature.

\section{Results and discussions}

\subsection{Structure and composition studies}

The wide-angle XRD analysis was performed for all the synthesized materials to identify crystal structure (Fig. 1a).
The OMC material exhibited two defined XRD peaks at $2 \theta$ values at around $23^{\circ}$ and $43^{\circ}$, which strongly signifies (002) and (100) plane of graphitic carbon [38].These peaks confirm the nano-casting method of synthesis lead to a perfect carbon material. The synthesized pure $\mathrm{MoS}_{2}$ material exhibited multiple XRD peaks at $2 \theta 14.8,33,40$ and $59^{\circ}$ correspond to (002), (100), (103) and (110) planes of a hexagonal phase of $\mathrm{MoS}_{2}$ [JCPDS no- 37-1492] respectively. $\mathrm{MoS}_{2}$-OMC possess weak XRD peaks in addition to OMC confirmed the composite material formation. The XRD pattern of the OMC in the $\mathrm{MoS}_{2}$-OMC composite illustrated that the addition of $\mathrm{Mo}, \mathrm{S}$ precursors and hydrothermal heat treatment doesn't alter the peak position. However, the diminished peak intensity of $\mathrm{OMC}$ and $\mathrm{MoS}_{2}$ was observed. The reason behind is the addition of $\mathrm{MoS}_{2}$ on the surface of OMC may cover the possible surface and hence reduces the well intense (002) plane intensity. Also, due to the vast surface area of the OMC, the formed $\mathrm{MoS}_{2}$ exhibits diminished size with fine dispersion. To quantify the particle size of the $\mathrm{MoS}_{2}$ using the Scherer equation, the major peak (002) was taken into the account. The result illustrated that the crystallite size of (002) peak is
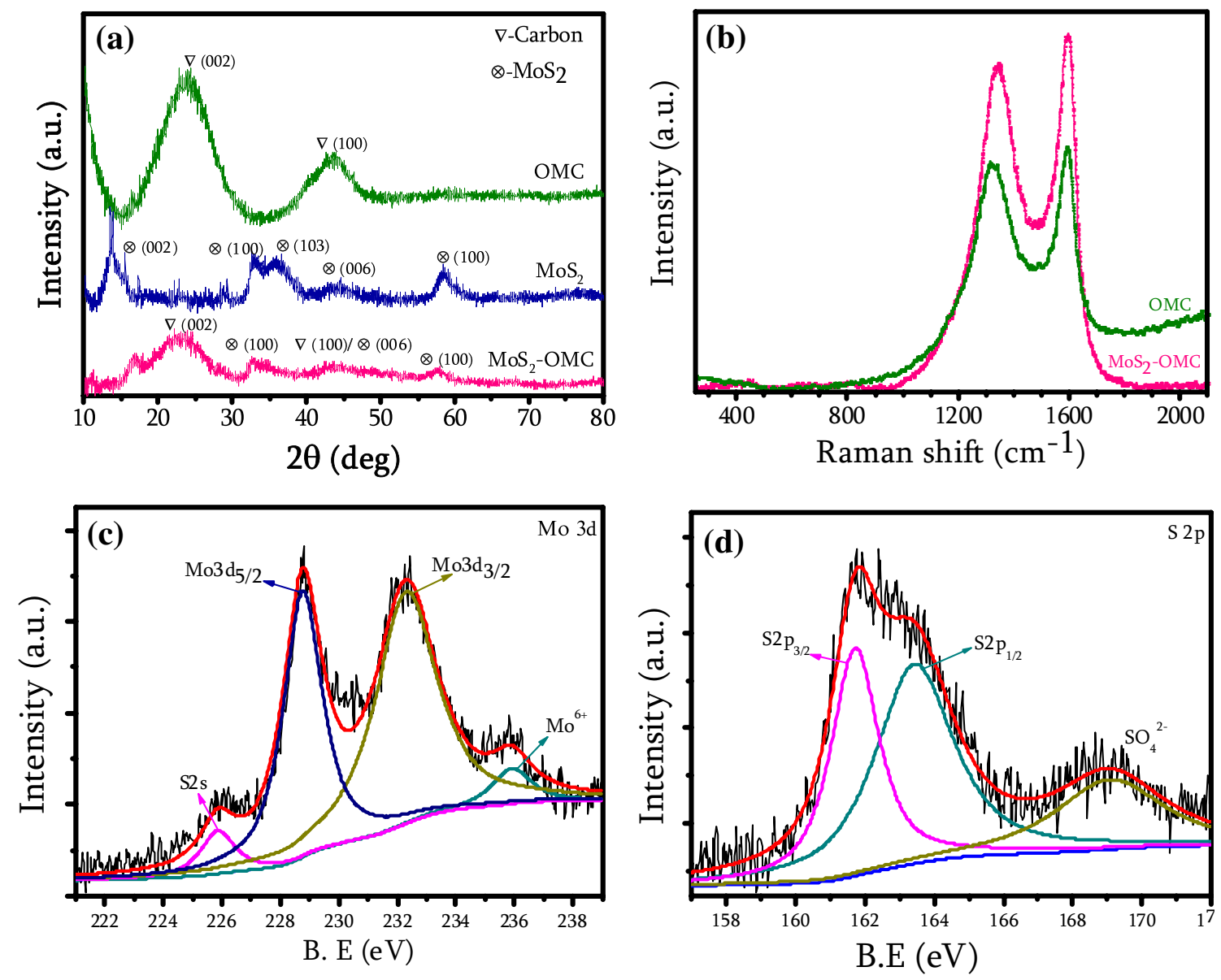

Fig. 1 a X-Ray diffraction pattern b Raman spectroscopy c, d XPS analysis of synthesized materials 
$1.056 \mathrm{~nm}$ for bare $\mathrm{MoS}_{2}$. Meanwhile, the major plane of $\mathrm{MoS}_{2}$ in the composite was not very pronounced due to the formation of small-sized nanoparticles on the surface of OMC. Hence, it is encountered difficulties in calculating the average crystallite size. The experimental error to the WAXS was carried for $\mathrm{MoS}_{2}$. The result illustrated that there is a minor experimental error when compared with the standard pattern. The error values in the angstrom unit $(\AA)$ are given in the closed brackets $a=3.1612(3)$, $b=3.1612(3)$, and $c=12.2985$ (4). Raman spectroscopy of $\mathrm{OMC}$ and $\mathrm{MoS}_{2}-\mathrm{OMC}$ materials were recorded to identify the unique Raman feature and formation of additional functional groups on the porous carbon by $\mathrm{MoS}_{2}$ (Fig. 1b). The spectra clearly showed two predominant peaks at 1593 and $1340 \mathrm{~cm}^{-1}$ for both OMC and composite materials. The peak centered at $1593 \mathrm{~cm}^{-1}$ corresponds to graphitic ( $\mathrm{G}$ band), occurred by the vibrations of $\mathrm{C}=\mathrm{C}$ bonds in a $2 \mathrm{D}$ hexagonal lattice and peak at $1340 \mathrm{~cm}^{-1}$ associated with defects and disorders in the structures in carbon materials ( $D$ band) [39]. The possible chemical states of the synthesized materials were analyzed by XPS, shown in Fig. 1c, d. The Mo XPS peaks demonstrated two peaks at 229.1 and $232.2 \mathrm{eV}$, corresponds to $\mathrm{Mo} \mathrm{d}_{5 / 2}$ and $\mathrm{Mo}_{3 / 2}$, of $\mathrm{Mo}^{4+}$ state. In addition to the $\mathrm{Mo}^{4+}$, two small peaks at around 226 and $236 \mathrm{eV}$ attributed to S $2 \mathrm{~s}$ and $\mathrm{Mo}^{6+}$ state. Meanwhile, XPS peaks of S $2 p$ indicated two high intense peaks at the binding energy value of 161.5 and $163.6 \mathrm{eV}$ corresponds to $S 2 p_{3 / 2}$ and $2 p_{1 / 2}$. From the XRD, Raman and XPS analysis results illustrate that all the materials exhibit its characteristic nature.

The morphology of SBA-15, OMC, $\mathrm{MoS}_{2}$ and $\mathrm{MoS}_{2}-\mathrm{OMC}$ were analyzed using FE-SEM and TEM analysis (Figs. 2 and 3). FE-SEM image of mesoporous SBA-15 illustrated a wheat-like structure (Fig. 2a) and a similar structural feature was also observed in the case of OMC materials (Fig. 2b). This observation indicated the formation of thriving porous carbon materials. $\mathrm{MoS}_{2}$ materials showed flower-like morphology with a large number of sheets connected (Fig. 2C). In the case of $\mathrm{MoS}_{2}-\mathrm{OMC}$ both wheat $(\mathrm{OMC})$ and flower $\left(\mathrm{MoS}_{2}\right)$ like structural observation confirming the formation of perfect composite materials (Fig. 2d). TEM analysis was performed to confirm in detailed structural information of the synthesized materials (Fig. 3a-d). The recorded images indicated that a welldefined porous nature of carbon material with numerous $\mathrm{MoS}_{2}$ flowers existing on its surface. The size varied $\mathrm{MoS}_{2}$, with many exposed sheets were well decorated on the porous carbon was seen from the composite TEM image. In our previous work, a similar trend of size varied $\mathrm{MoS}_{2}$ formation over the interconnected porous carbon was observed [40]. The particle size distribution of $\mathrm{MoS}_{2}$ in the composite material was calculated and shown in the histogram (Fig. 3d). These results illustrated that averages mean diameter of the $\mathrm{MoS}_{2}$ exists on the OMC surface is equal to $0.44 \mu \mathrm{m}$.
Fig. 2 FE-SEM images of a SBA-15, b OMC c MoS 2 and d $\mathrm{MoS}_{2}-\mathrm{OMC}$

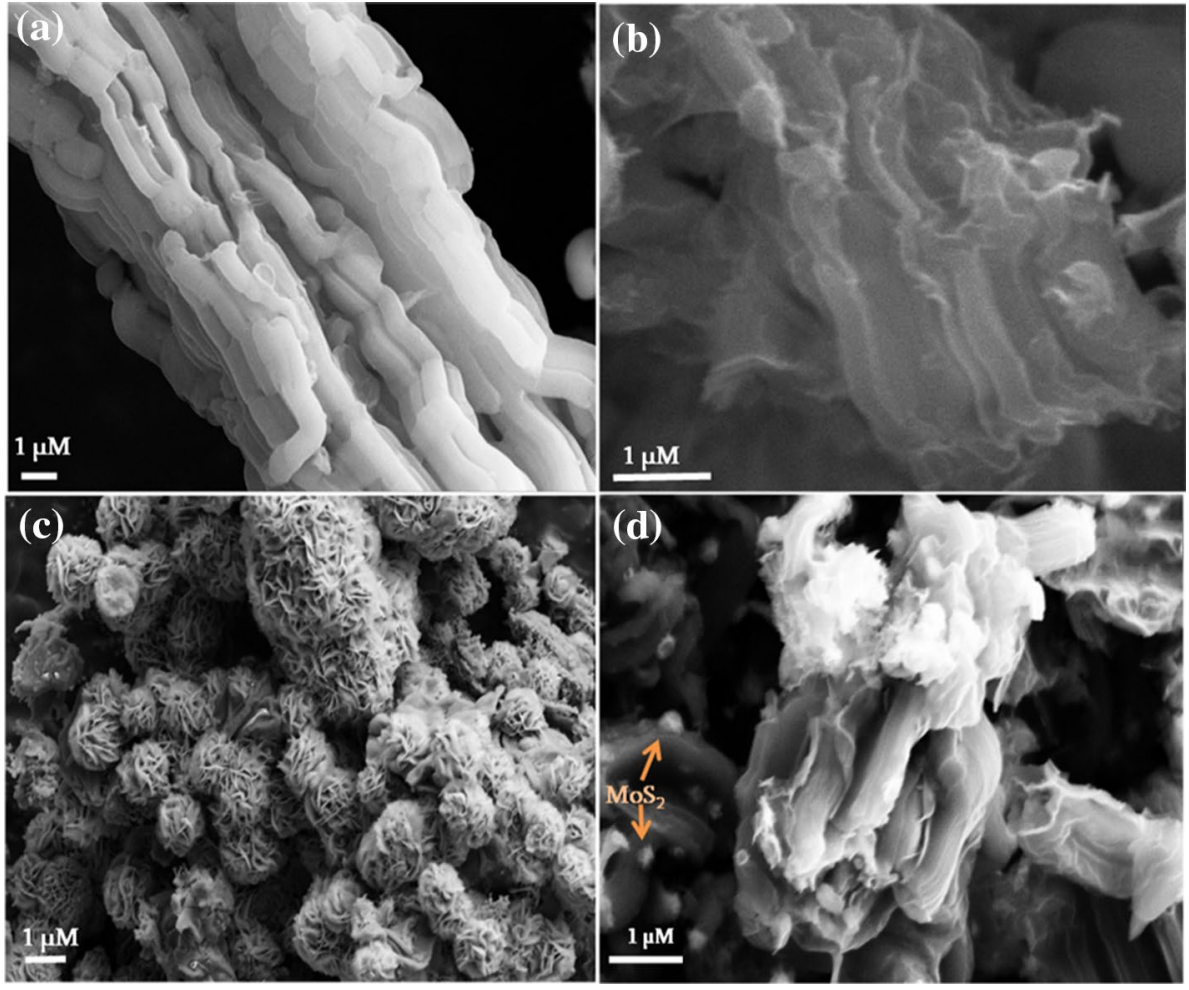


Fig. 3 TEM images of $\mathbf{a} \mathrm{OMC}, \mathbf{b}$ $\mathrm{MoS}_{2}-\mathrm{OMC}$ and $\mathbf{c}$ Isolated $\mathrm{MoS}_{2}$ and $\mathbf{d}$ Particle size distribution
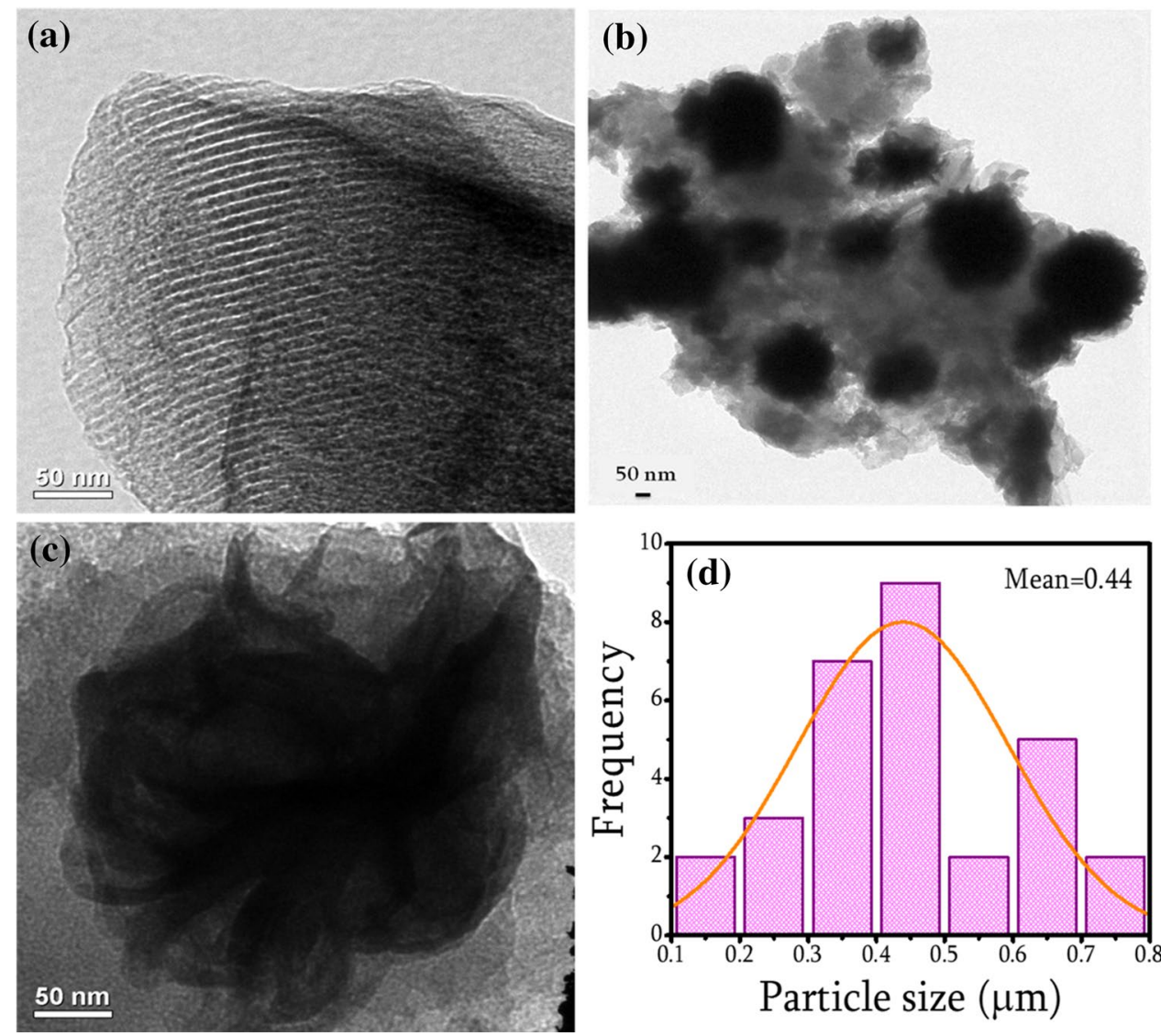

\subsection{Electrochemical characterization of the synthesized materials}

To verify the surface sensitivity of the electrodes, an inner-sphere electrochemical $\left.\left[\mathrm{Fe}(\mathrm{CN})_{6}\right]^{3-/ 4-}\right]$ redox probe is widely used to characterize the electrochemical characteristics of the synthesized materials. Figure $4 a$ shows the comparison of cyclic voltammetric (CVs) responses in $0.1 \mathrm{M}$ $\mathrm{KNO}_{3}$ solution containing $5 \mathrm{mM}$ of $\left[\mathrm{Fe}(\mathrm{CN})_{6}\right]^{3 / 4-}$ at a scan rate of $50 \mathrm{mV} / \mathrm{s}$ for different synthesized material modified GCE. CV at bare GCE showed a redox peak with a peak potential difference ( $\Delta \mathrm{Ep}$ ) of $125 \mathrm{mV}$ indicating a quasireversible redox reaction. However, the $\mathrm{CV}$ obtained using $\mathrm{MoS}_{2} / \mathrm{GCE}$ does not exhibit any redox behavior under similar experimental conditions. But OMC/GCE showed high capacitive behavior with decreased peak potential difference $(\triangle \mathrm{Ep})$ of $90 \mathrm{mV}$.

However, $\mathrm{MoS}_{2}$-OMC/GCE showed well-defined redox behavior with a decreased peak to peak potential difference $(\Delta \mathrm{Ep})$ of $77 \mathrm{mV}$. Besides, enhancement of 1.5 times of peak current is also observed compared to the bare GC electrode. Figure $4 \mathrm{~b}$ shows the real and imaginary parts of the impedance spectra represented as Nyquist plots $\left(Z_{\text {im }}\right.$ vs. $Z_{\text {re }}$ for bare, $\mathrm{MoS}_{2}$, OMC and $\mathrm{MoS}_{2}$-OMC/GCE's recorded in $0.1 \mathrm{M} \mathrm{PBS}(\mathrm{pH} 7)$ containing $5 \mathrm{mM}\left[\mathrm{Fe}(\mathrm{CN})_{6}\right]^{3-/ 4-}$. From the best-fitted model, the charge transfer resistance $\left(R_{c t}\right)$ values were calculated. In Fig. $4 \mathrm{~b}$, bare GCE exhibited enlarged semicircle with an $R_{c t}$ value of $1423 \Omega$, indicating the sluggish kinetic process. The $R_{c t}$ value observed at $\mathrm{MoS}_{2} / \mathrm{GCE}$ and OMC/GCE electrode are $336 \Omega$ and 125 $\Omega$ respectively. However, as shown in figure $\mathrm{MoS}_{2}-\mathrm{MC} /$ GCE doesn't show any well-defined semicircle in the examined frequency range, instead of a slightly curved line indicating the diffusion-limited process with an $\mathrm{R}_{\mathrm{ct}}$ value of 5 $\Omega$. These mutual results confirmed that $\mathrm{MoS}_{2}-\mathrm{OMC}$ composite has good electron transfer ability at the interface.

\subsection{Electrochemical determination of hydrazine}

The electrochemical properties of the $\mathrm{MoS}_{2}-\mathrm{OMC}$ material were investigated using CV experiments. The $0.1 \mathrm{M}$ PBS is used to elucidate the electron transfer characteristics of the material in a three-electrode configuration. The capacitance value of the electrode $\left(C_{0}\right)$ was derived from cyclic voltammograms in $0.1 \mathrm{M} \mathrm{PBS}$ [Fig. 5a] using the relationship $\mathrm{CCV}=\mathrm{i} /(\mathrm{sv})$. Here, $\mathrm{CCV}$ is the capacitance $\left(\mathrm{F} \mathrm{cm}^{-2}\right)$, ' $\mathrm{i}$ ' is the average charge or discharge current (A), ' $s$ ' is the active electrode surface area $\left(\mathrm{cm}^{2}\right)$, and ' $v$ ' is the scan rate $\left(\mathrm{Vs}^{-1}\right)$. The double-layer capacitance of bare GCE, $\mathrm{MoS}_{2}-\mathrm{OMC}$ material modified electrodes were 

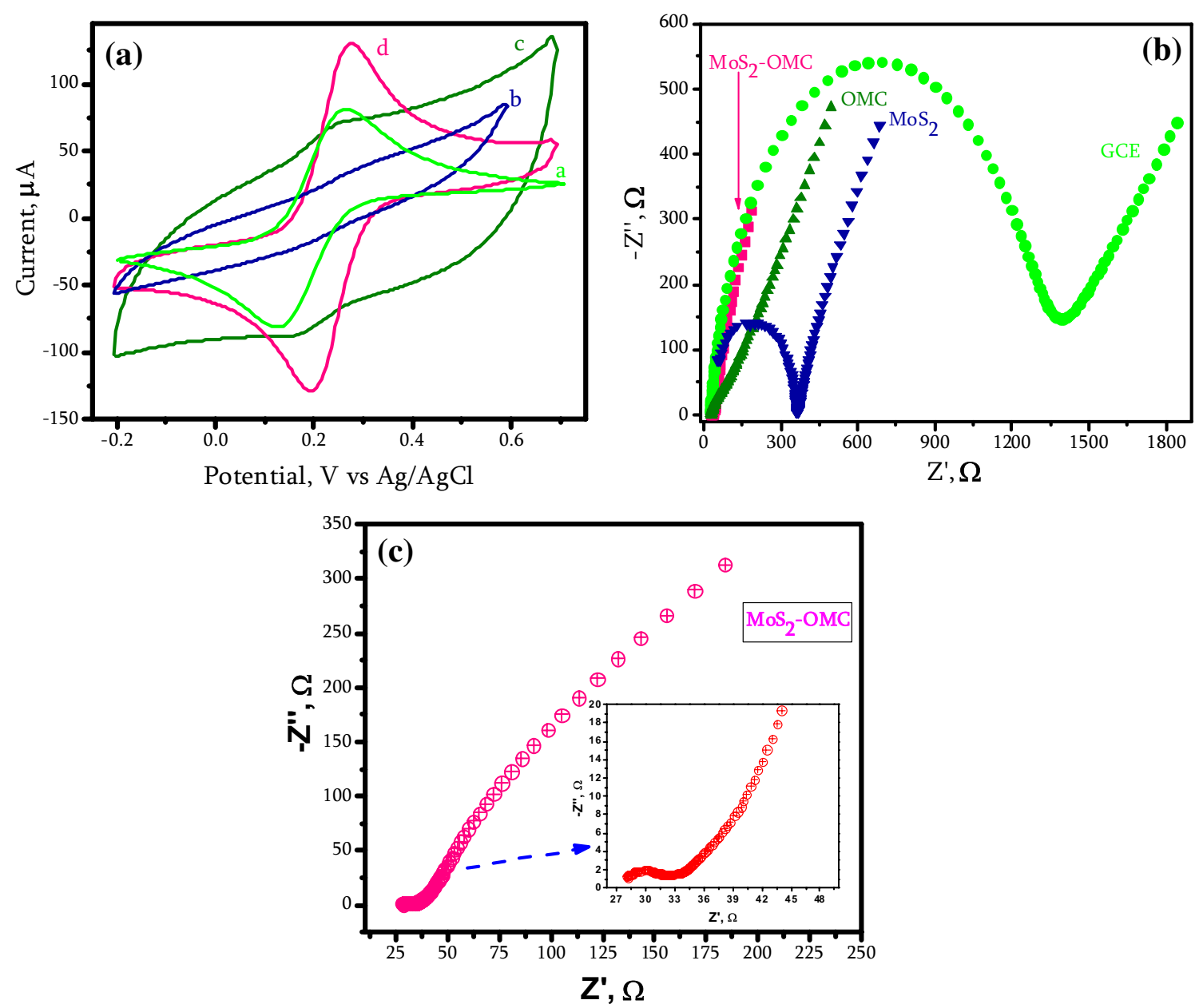

Fig. 4 a CVs obtained for (a) Bare GCE, b $\mathrm{MoS}_{2} / \mathrm{GCE}$, c OMC/GCE, and $\mathbf{d ~} \mathrm{MoS}_{2}-\mathrm{OMC} / \mathrm{GCE}$ in presence of $5 \mathrm{mM}\left[\mathrm{Fe}(\mathrm{CN})_{6}\right]^{3-/ 4-}$ in $0.1 \mathrm{M}$ $\mathrm{KNO}_{3}$ electrolyte at scan rate $50 \mathrm{mVs}^{-1} \mathbf{b}$ Nyquist plots of respective

calculated from the CV curves and the values are 128 and $365 \mu \mathrm{F} \mathrm{cm}{ }^{-2}$ respectively. Interestingly, the $\mathrm{MoS}_{2}-\mathrm{OMC} /$ GCE showed a capacitance value of $365 \mu \mathrm{F} \mathrm{cm}{ }^{-2}$, which is three-fold higher than that of GCE. As discussed earlier, the $\mathrm{MoS}_{2}$ and $\mathrm{sp}^{2}$-hybridized structure of carbon might contribute to the high capacitance value in the composite structure. The $\mathrm{MoS}_{2}$ material with carbon may serve as a promising material for novel functionalized electrodes and supercapacitor applications. To evaluate the electrochemical sensing ability of $\mathrm{MoS}_{2}$-OMC/GCE for hydrazine oxidation, $\mathrm{CV}$ experiments were performed. All other electrodes $\mathrm{MoS}_{2} / \mathrm{GCE}, \mathrm{OMC} / \mathrm{GCE}$, and bare GCE were also evaluated in the presence of $1.5 \mathrm{mM}$ hydrazine (Fig. $5 \mathrm{~b}$ ). A very small oxidation peak at $0.8 \mathrm{~V}$ was observed for bare GCE indicated minimal electrochemical behavior at high overpotential. The CV curve obtained for OMC/ GCE also showed a large overpotential with a drawnout peak at about $0.38 \mathrm{~V}$, though the current response slightly increased compared to the bare GCE. However, materials modified GCE and bare GCE c Nyquist plots of $\mathrm{MoS}_{2}-\mathrm{OMC}$ alone in $0.1 \mathrm{M} \mathrm{KNO}_{3}$ solution containing $5 \mathrm{mM}\left[\mathrm{Fe}(\mathrm{CN})_{6}\right]^{3-/ 4-}(1: 1)$

significant small overpotential $0.15 \mathrm{~V}$ was observed compared to bare GCE, with an increase in the peak current of $50.4 \mu \mathrm{A}$ for $\mathrm{MoS}_{2} / \mathrm{GCE}$. In the case of $\mathrm{MoS}_{2}-\mathrm{OMC} / \mathrm{GCE}$, a sharp oxidation peak was observed at $0.381 \mathrm{~V}$. The peak current was about two times higher than that of bare GCE. The overall $0.42 \mathrm{~V}$ negative shift of the peak potential indicated the catalytic activity of the electrode with the following order $\mathrm{MoS}_{2}-\mathrm{OMC} / \mathrm{GCE}>\mathrm{MoS}_{2} / \mathrm{GCE}>\mathrm{OMC} /$ GCE > bare GCE. The reversibility of the electron transfer process and surface accumulation of the electroactive species led to an increased current response.

\subsubsection{Scan rate effect}

The scan rate effect of $\mathrm{MoS}_{2}-\mathrm{OMC} / \mathrm{GCE}$ was studied in the potential range from 20 to $100 \mathrm{mVs}^{-1}$ using a $0.1 \mathrm{M} \mathrm{PBS}$ containing $1 \mathrm{mM}$ hydrazine (Fig. 6a). The results illustrated that the positive potential current increases linearly with the square root of the scan rate, also the peak potential 

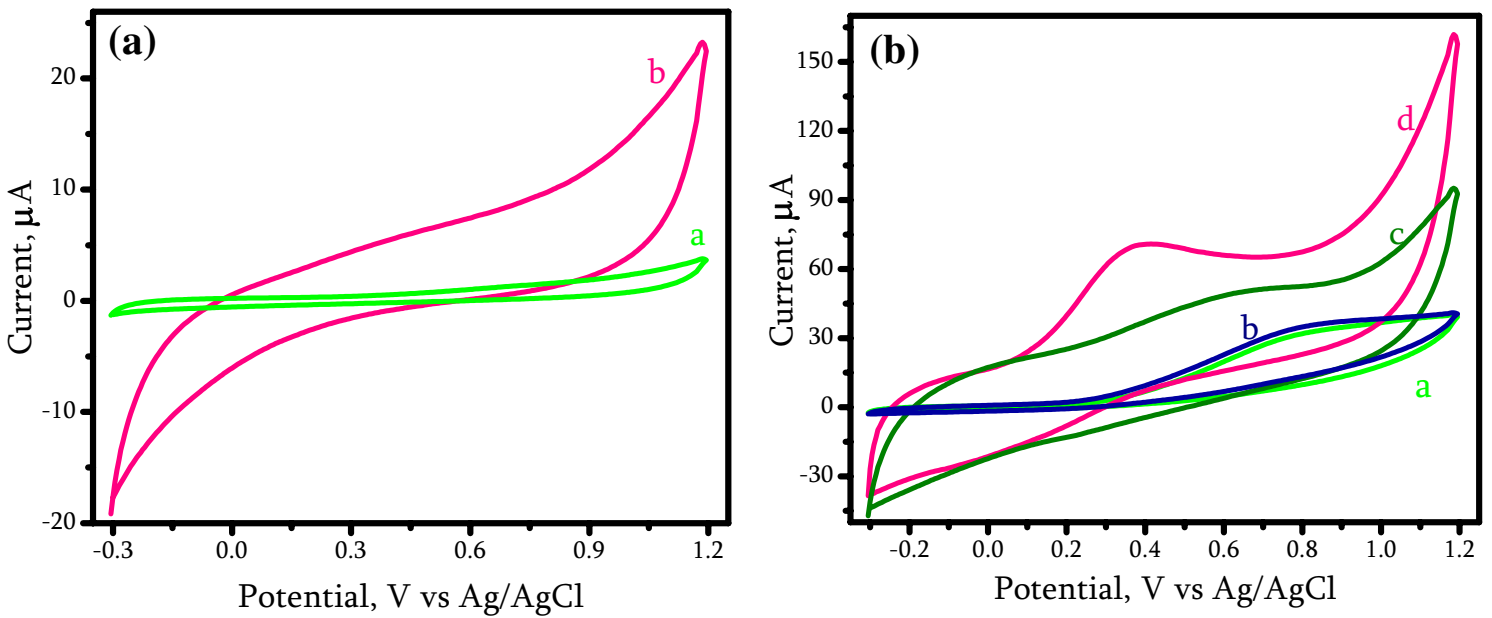

Fig. 5 a CV response of Bare GCE a MoS - OMC modified GCE $\mathbf{b}$ in $0.1 \mathrm{M} \mathrm{PBS}$ alone at a scan rate of $50 \mathrm{mVs}^{-1}$. b CVs of $1.5 \mathrm{mM}$ hydrazine contain $0.1 \mathrm{M} \mathrm{PBS}(\mathrm{pH} 7.0)$ at bare GCE a MoS 2 /GCE b OMC/GCE c and $\mathrm{MoS}_{2}-\mathrm{OMC/GCE} \mathrm{d} \mathrm{Scan} \mathrm{rate:} 50 \mathrm{mVs}^{-1}$

shifted slightly towards the positive direction with the scan rate. The diffusion-controlled kinetics was confirmed by the linear changes of peak current with the square root of the scan rate $\left(v^{1 / 2}\right),\left(R^{2}=0.99\right)$. This is due to the different entities of mesoporous carbon and $\mathrm{MoS}_{2}$ exhibited on the GCE surface. The fast electron transfer in $\mathrm{MoS}_{2}$ and better electrochemical behavior were also reported due to the presence of sharp edge plane in $\mathrm{MoS}_{2}$ catalyst materials. Thus, it is concluded that fast electron transfer kinetics of these materials could be attributed to the presence of sharp edges of composite materials. Furthermore, linear behavior between the plots of log current versus log scan rate with a gradient value of 0.34 (Fig. 6c) confirmed the pure diffusion-controlled process [41].

Based on the voltammetric response, it is expected that amperometric detection of hydrazine by $\mathrm{MoS}_{2}-\mathrm{OMC} / \mathrm{GCE}$ is a promising approach. An enhanced current value will be observed from the amperometric analysis under stirred conditions was expected. This can be used to estimate the lower limit of detection of hydrazine. Figure 7a illustrated the typical amperometric experiments with successive addition of hydrazine, under conditions at which the potential of $\mathrm{MoS}_{2}-\mathrm{OMC} / \mathrm{GCE}$ was kept at $0.38 \mathrm{~V}$ vs. $\mathrm{Ag} / \mathrm{AgCl}$. The result indicated that a well-defined hydrazine oxidation pattern was observed during the successive addition of $1 \mu \mathrm{M}$ of hydrazine. The current value is increased with hydrazine concentration (Fig. 7b). The obtained calibration plot was linear for a wide concentration range of 1-9 $\mu \mathrm{M}$ with a slope value of $0.27 \mu \mathrm{A} / \mu \mathrm{M}$ (sensitivity) and a correlation coefficient $\left(R^{2}\right)$ of 0.99 . The detection limit was found to $0.4 \mu \mathrm{M}$ where the signal to noise ratio is observed as 3 .

\subsubsection{Interference study}

Non-enzymatic electrochemical determination of hydrazine using $\mathrm{MoS}_{2}-\mathrm{OMC} / \mathrm{GCE}$ has not reported so far. The revealed electrocatalytic results of the prepared composite materials are quite interesting for the development of a novel sensor matrix for hydrazine determination. However, a real-time problem is the interference effect during the determination. The well-known interfering compounds such as nitrate, ammonia, and other cations which are all often accompanying with hydrazine. Meanwhile, lowering the detection potential of hydrazine might be the right choice for minimizing the interference effect. Therefore, the inference effect of the modified electrode was performed with a three-fold higher concentration of $\mathrm{Na}^{+}$, $\mathrm{Ca}^{2+}, \mathrm{Ni}^{2+}, \mathrm{Cu}^{2+}, \mathrm{NH}_{3}$, Nitrate, and $\mathrm{H}_{2} \mathrm{O}_{2}$. Interestingly, the composite electrode does not show any significant electrochemical performance with the interfering molecules (Fig. 8).

\subsubsection{Stability and reproducibility of $\mathrm{MoS}_{2}-\mathrm{OMC} / \mathrm{GCE}$}

The stability of the fabricated sensor platform is an important parameter for deciding the sensor activity. The stability of $\mathrm{MoS}_{2}-\mathrm{OMC} / \mathrm{GCE}$ was examined for 2-weeks. All the prepared samples were stored in 0.1 M PBS $(\mathrm{pH}-7.0)$ at $4{ }^{\circ} \mathrm{C}$. The electrochemical sensing results illustrated that a remarkable constant current response was reported for everyday use. Therefore, it is concluded that under the experimental conditions, the developed sensor showed good reproducibility and prolong stability. The constant stability of the electrode is correlated with the composite $\mathrm{MoS}_{2}-\mathrm{OMC}$ structure. The increased surface and nanoporous nature of OMC inferred an enhanced formation 

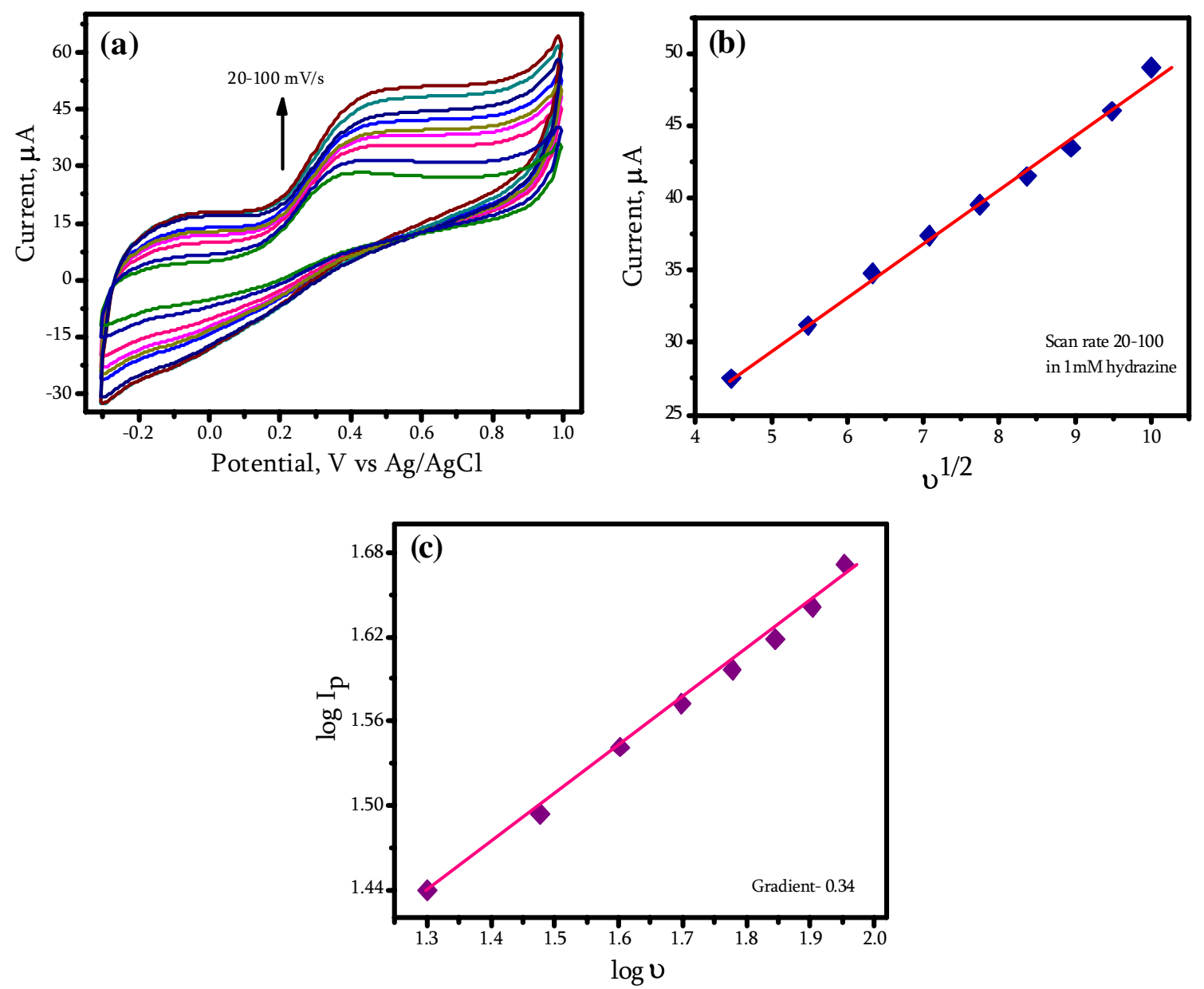

Fig. 6 a CV response of $\mathrm{MoS}_{2}-\mathrm{OMC} / \mathrm{GCE}$ in the presence of $1 \mathrm{mM}$ hydrazine at different scan rate ranges from $20-100 \mathrm{mVs}^{-1}$ b Corresponding peak current vs. square root of scan rate $\left(v^{1 / 2}\right)$, c Plot of log Ip vs log $v$

Fig. 7 Amperometric determination of hydrazine at $\mathrm{MoS}_{2}$-OMC modified GCE

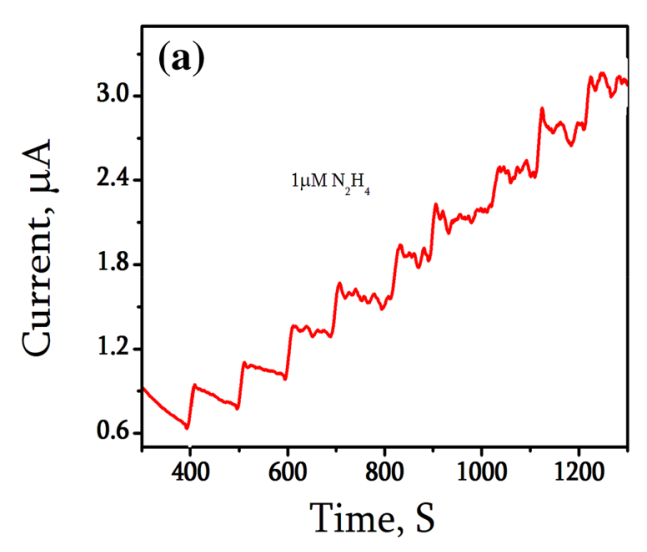

of active $\mathrm{MoS}_{2}$ species, which is the main route cause for the enhanced electron transfer processes. To validate the reproducibility of the composite electrode a series of repetitive measurements were also carried out in $1 \mathrm{mM}$ hydrazine solution. The obtained relative standard deviation (R.S.D.) of $4 \%$ for 20 replicate determinations for hydrazine indicated that the electrodes exhibited well characteristic sensing behavior. 


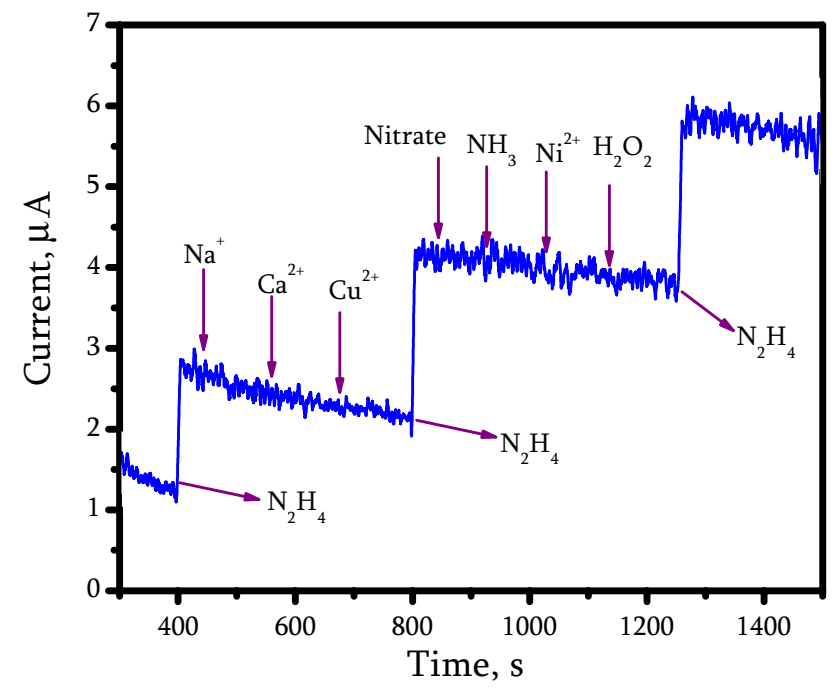

Fig. 8 The amperometric response of $\mathrm{MoS}_{2}$-OMC/GCE for $10 \mu \mathrm{M}$ hydrazine and three-fold concentration of different interfering species $\mathrm{Na}^{+}, \mathrm{Ca}^{2+}, \mathrm{Cu}^{2+}$, hydrogen peroxide, nitrate and ammonia in $0.1 \mathrm{M}$ PBS $(\mathrm{pH}=7)$

\section{Conclusions}

The present work describes the development of an electrochemical sensor for hydrazine detection using $\mathrm{MoS}_{2}-\mathrm{OMC}$ nanocomposite material. Surface analytical tools revealed the existence of the vast surface of OMC facilitated the dispersion of Mo and S precursors. It allowed the growth of $\mathrm{MoS}_{2}$ in well-isolated spaces of vast surface edges. In an electrochemical environment, the targeted molecule freely coordinated on the surface and rapidly interacts while applying the set potential. The present nanocomposite exhibited an impressive electrochemical activity and maybe the choice of electrode material for sensing hydrazine molecules.

Acknowledgements Author CS thank CSIR-CECRI in-house start-up project (IHP-0091), Fast track Translational project (MLP-0102) and Central Instrumentation Facility Division of CSIR-CECRI. SM greatly acknowledge to K. L. E. F for providing internal funding (File No-KLEF/ IF/FEB/2019-2020/005).

\section{Compliance with ethical standards}

Conflict of interest The authors declare that they have no competing interests.

\section{References}

1. Steinhoff D, Mohr U (1988) The question of carcinogenic effects of hydrazine. Exp Pathol 33:133-143
2. Yamada K, Yasuda K, Fujiwara N, Siroma Z, Tanaka H, Miyazaki Y (2003) Potential application of anion-exchange membrane for hydrazine fuel cell electrolyte. Electrochem Commun 5:892-896

3. Hao Y, Zhang Y, Ruan K, Chen W, Zhou B, Tan X, Wang Y, Zhao L, Zhang G, Qu P, Xu M (2017) A naphthalimide-based chemodosimetric probe for ratiometric detection of hydrazine. Sens Actuators, B 244:417-424

4. Malone HE (1961) Determination of mixtures of hydrazine and 1,1-dmethylhydrazine. Anal Chem 33:575-577

5. Mo JW, Ogorevc B, Zhang XJ, Pihlar B (2000) Cobalt and copper hexacyanoferrate modified carbon fiber microelectrode as an all solid potentiometric microsensor for hydrazine. Electroanalysis 12:48-54

6. Sun M, Bai L, Liu DQ (2009) A generic approach for the determination of trace hydrazine in drug substances using in situ derivatization-headspace GC-MS. J Pharm Biomed Anal 49:529-533

7. Zen JM, Kumar AS, Wang HF (2000) A dual electrochemical sensor for nitrite and nitric oxide. Analyst 125:2169-2172

8. Ahmad R, Tripathy N, Ahn MS, Hahn YB (2017) Highly stable hydrazine chemical sensor based on vertically-aligned $\mathrm{ZnO}$ nanorods grown on electrode. J Colloid Interf Sci 494:153-158

9. Vellaichamy B, Periakaruppan P, Ponnaiah SK (2017) A new in situ synthesized ternary CuNPs-PANI-GO nano composite for selective detection of carcinogenic hydrazine. Sens Actuators, B 245:156-165

10. Daemi S, Ashkarran AA, Bahari A, Ghasemi S (2017) Fabrication of a gold nanocage/graphene nanoscale platform for electrocatalytic detection of hydrazine. Sens Actuators, B 245:55-65

11. Gupta R, Rastogi PK, Ganesan V, Yadav DK, Sonkar PK (2017) Gold nanoparticles decorated mesoporous silica microspheres: a proficient electrochemical sensing scaffold for hydrazine and nitrobenzene. Sens Actuators, B 239:970-978

12. Mutyala S, Mathiyarasu J (2015) Preparation of graphene nanoflakes and its application for detection of hydrazine. Sens Actuators, B 210:692-699

13. Zhang S, Geryak R, Geldmeier J, Kim S, Tsukruk VV (2017) Synthesis, assembly, and applications of hybrid nanostructures for biosensing. Chem Rev 117:12942-13038

14. Campuzano S, Pedrero M, Nikoleli GP, Pingarrón JM, Nikolelis DP (2017) Hybrid 2D-nanomaterials-based electrochemical immunosensing strategies for clinical biomarkers determination. Biosens Bioelectron 89:269-279

15. Liu RX, Wang H, Wu Y, Lu Z (2018) High-performance hybrid electrode decorated by well-aligned nanograss arrays for glucose sensing. Biosens Bioelectron 102:288-295

16. Ali MA, Mokaram AA, Yahya $R$, Abdi MM, Nabi $H$, Mahmud ME (2017) The development of non-enzymatic glucose biosensors based on electrochemically prepared polypyrrole-chitosantitanium dioxide nanocomposite films. Nanomaterials 7:129

17. Chen S, Chi M, Yang Z, Gao M, Wang C, Lu X (2017) Carbon dots/ $\mathrm{Fe}_{3} \mathrm{O}_{4}$ hybrid nanofibers as efficient peroxidase mimics for sensitive detection of $\mathrm{H}_{2} \mathrm{O}_{2}$ and ascorbic acid. Inorg Chem. Front 4:1621-1627

18. Vanegas DC, Taguchi M, Chaturvedi P, Burrs S, Tan M, Yamaguchi H, McLamore ES (2014) A comparative study of carbon-platinum hybrid nanostructure architecture for Amperometric biosensing. Analyst 139:660-667

19. Gong C, Zhang Y, Chen W, Chu J, Lei T, Pu J, Dai L, Wu C, Zhai T, Xiong J (2017) Electronic and optoelectronic applications based on 2D novel anisotropic transition metal dichalcogenides. Adv Sci 4:1700231

20. Lemme MC, Li LJ, Palacios T, Schwierz F (2014) Two-dimensional materials for electronic applications. Mat Res Bull 39:1-7

21. Ji W, Chu X, Zhang S, Wang D, Ma Y (2018) Active basal plane in ZT-phased MX2 ( $M=M o, W ; X=S, S e, T e)$ catalysts for the 
hydrogen evolution reaction: a theoretical study. Int J Hydrog Energy 43:19432-19437

22. Jeong G, Kim CH, HurYG Han GH, Lee SH, Lee KY (2018) Nidoped MoS2 nanoparticles prepared via core-shell nanoclusters and catalytic activity for upgrading heavy oil. Energy Fuels 32:9263-9270

23. Lu C, Liu Y, Ying Y, Liu J (2017) Comparison of $\mathrm{MoS}_{2}, \mathrm{WS}_{2}$, and graphene oxide for DNA adsorption and sensing. Langmuir 33:630-637

24. Barua S, Dutta HS, Gogoi S, Devi R, Khan R (2018) Nanostructured $\mathrm{MoS}_{2}$-based advanced biosensors: a review. ACS Appl. Nano Mater 1:2-25

25. Muhammad SJ, Shuge D, Mingjun W, Donglin G, Lin C, Xue W, Chenguo H, Yi X (2015) High performance solid state flexible supercapacitor based on molybdenum sulfide hierarchical nanospheres. J Power Sources 285:63-69

26. Yasir A, Sining $Y$, Muhammad SJ, Jiageng $C$, Muhammad FT, Ziqi W, Chao Y, Asim A, Shahid H (2020) Anchoring 2D NiMoO 4 nanoplates on flexible carbon cloth as a binder-free electrode for efficient energy storage devices. Ceram Int 46:4470-4476

27. Chen Y, Xi J, Liu Z, Suenaga K, Wang D, Shuai Z, Huang YS, Xie $L$ (2013) Tunable band gap photoluminescence from atomically thin transition-metal dichalcogenide alloys. ACS Nano 7:4610-4616

28. Kang M, Kim B, Ryu SH, Jung SW, Kim J, Moreschini L, Jozwiak C, Bostwick E, Kim KS (2017) Universal mechanism of band-gap engineering in transition-metal dichalcogenides. Nano Lett 17:1610-1615

29. Suh J, Tan TL, Zhao W, Park J, Lin DY, Park TE, Kim J, Jin C, Saigal N, Ghosh S, Wong ZM, Chen Y, Wang F, Walukiewicz W, Eda G, Wu $J$ (2018) Reconfiguring crystal and electronic structures of $\mathrm{MoS}_{2}$ by substitutional doping. Nat Comm 9:199

30. Muhammad Z, Haifeng KM, Wu C, Rehman Z, Habib M, Sun Z, Wu X (2018) Electron doping induced semiconductor to metal transitions in $\mathrm{ZrSe}_{2}$ layers via copper atomic intercalation. Nano research 11:4914-4922

31. Guo T, Sampat S, Zhang K, Robinson JA, Rupich SM, Chabal YJ, GartsteinYN Malko AV (2017) Order of magnitude enhancement of monolayer $\mathrm{MoS}_{2}$ photoluminescence due to near-field energy influx from nanocrystal films. Sci Rep 7:41967

32. Cao X, Ding C, Zhang C, Gu W, Yan Y, Shi X, Xian Y (2018) Boronic acid-functionalized molybdenum disulfide quantum dots for the ultrasensitive analysis of dopamine based on synergistic quenching effects from IFE and aggregation. J Mater Chem B 6:8011-8036

33. Lee J, Dak P, Lee Y, Park H, Choi W, Alam MA, Kim S (2014) Twodimensional layered $\operatorname{mos}_{2}$ biosensors enable highly sensitive detection of biomolecules. Sci Rep 4:7352

34. Zhang W, Zhang P, Su Z, Wei G (2015) Synthesis and sensor applications of $\mathrm{MoS}_{2}$-based nanocomposites. Nanoscale 7:18364-18378

35. Sun J, Li X, Guo W, Zhao M, Fan X, Dong Y, Xu C, Deng J, Fu Y (2017) Synthesis methods of two-dimensional $M_{2} S_{2}$ : a brief review. Crystals 7:198

36. Suresh C, Mutyala S, Mathiyarasu J (2016) Support interactive synthesis of nanostructured $\mathrm{MoS}_{2}$ electrocatalyst for oxygen reduction reaction. Mat Lett 164:417-420

37. Suresh C, Santhanaraj D, Gurulakshmi M, Deepa G, Selvaraj M, Sasi Rekha NR, Shanthi K (2012) Mo-Ni/Al-SBA-15 (sulfide) catalysts for hydrodenitrogenation: effect of $\mathrm{Si} / \mathrm{Al}$ ratio on catalytic activity. ACS Catal 2:127-134

38. Zhang B, Zhou Q, Wang Y, Song N, Ni L (2017) Synthesis of ordered mesoporous carbon using m-Diethynylbenzene as a new precursor. Mater Lett 189:317-320

39. Lee CW, Yoon SB, Kim HK, Youn HC, Han J, Roh KC, Kim KB (2015) A two-dimensional highly ordered mesoporous carbon/graphene nanocomposite for electrochemical double layer capacitors: effects of electrical and ionic conduction pathways. J Mater Chem A 3:2314-2322

40. Mutyala S, Kinsly J, Sharma GVR, Chinnathambi S, Jayaraman M (2018) Non-enzymatic electrochemical hydrogen peroxide detection using $\mathrm{MoS}_{2}$-interconnected porous carbon heterostructure. J. Electroana Chem 823:429-436

41. Sims MJ, Rees NV, Dickinson EJF, Compton RG (2010) Effects of thin-layer diffusion in the electrochemical detection of nicotine on basal plane pyrolytic graphite (BPPG) electrodes modified with layers of multi-walled carbon nanotubes. Sens Actuators, B 144:153-158

Publisher's Note Springer Nature remains neutral with regard to jurisdictional claims in published maps and institutional affiliations. 